\title{
Pilot Study of the Use of Personal Carbon Monoxide Monitoring to Achieve Radical Smoking Reduction
}

\author{
Emma Beard and Robert West \\ Cancer Research UK Health Behaviour Research Centre, University College London, UK
}

\begin{abstract}
$B^{3}$ ackground and aims: This study examined whether providing smokers with a personal monitor for measuring expired-air carbon monoxide (CO) concentrations would be a feasible method of achieving a reduction in smoke intake. Methods: Ten smokers were given a CO monitor and asked to use it regularly throughout the day for 6 weeks with the aim of maintaining their CO reading below 10 ppm. They were advised to use nicotine replacement therapy, but this was not provided. At baseline and follow-up, smokers were asked to comment on their use of the monitors and motivation to stop smoking. Demographic characteristics, cigarette consumption, and nicotine dependence, was also assessed. Additionally, during the first 2 weeks participants were instructed to record how often they used their CO monitor, their average readings and cigarette consumption. Results: Eight smokers had an average daily $\mathrm{CO}$ concentration below their baseline on at least $93 \%$ of the days in the 2 weeks of daily monitoring, while three had CO levels below 10 ppm on 36\% of the days. At the 6-week follow-up, all participants' $\mathrm{CO}$ concentrations were below their baseline value; two were below $10 \mathrm{ppm}$. Average daily cigarette consumption reduced from 14.1 (SD6.03) at baseline to 9.8 (SD 4.95) during the 2 weeks of daily CO monitoring ( $t=2.46, d f 9, p=0.036)$ and $9.5(S D 5.50)$ at 6 weeks follow-up $(t=1.73$, df 7 , $p=0.127)$. Use of the $\mathrm{CO}$ monitors was generally found to be acceptable and to increase motivation to stop smoking completely. Five smokers attempted to quit smoking. Conclusions: Regular personal CO monitoring may be a useful method for reducing smokers' cigarette intake and increasing their motivation to stop completely. A controlled trial with long-term follow up is warranted.
\end{abstract}

Keywords: smoking reduction, NRT, carbon monoxide, self-monitoring

Significantly reducing cigarette intake with the aid of NRT on a sustained basis may reduce harm and promote cessation (Moore et al., 2009; Beard et al., 2011). It is therefore of interest to determine how reliable reductions can be attained. A substantial amount of the literature on health behaviour change points towards the utility of self-regulatory techniques (Michie, Abraham, Whittington, McAteer, \& Gupta, 2009; Michie, Hyder, Walia, \& West, 2011; Helzer, Badger, Rose, Mongeon, \& Searles, 2002; Quinn et al., 2010; McAteer, Stone, Roberts, \& Michie, 2007; Becona \& Vazquez, 2001; Barton, Blanchard, \& Veazey, 1999). According to Control Theory this involves: (1) setting realistic goals, (2) reviewing these goals, (3) monitoring behaviour, (4) receiving feedback, and (5) intention formation (Carver \& Scheier, 1981, 1982).

Smokers appear to find two of these techniques particularly difficult: the setting of attainable goals and monitoring performance (Sayette, 2004; Beard, Vangeli, Michie, \& West, in press). This is partially because cigarette consumption is an unreliable method of monitoring smoke intake. There is an extensive body of evidence that smokers often modify how they smoke their cigarettes, such as puff frequency, despite failing to reduce cigarette consumption (Beard, Fidler, \& West, 2011; Beard et al., in press; Fagerstrom \& Hughes, 2002). Smokers also fail to set difficult, realistic, and specific goals, which according to Goal

Address for correspondence: Emma Beard, Cancer Research UK Health Behaviour Research Centre, University College London, WC1E 6BP. E-mail: e.beard@ucl.ac.uk 
Setting Theory is pivotal for optimal performance (Locke \& Lantham, 2004; Locke \& Lantham, 1990; Abraham \& Michie, 2008).

We examined whether providing smokers with a personal monitor for measuring expired-air $\mathrm{CO}$ concentrations, and a clear goal of maintaining smoke intake below $10 \mathrm{ppm}$ at all times, would be a feasible method of achieving a reduction in smoke intake. CO is a colourless, odourless, and tasteless gas, that combines with haemoglobin in place of oxygen. It is one of the many compounds produced by cigarettes and appears to be a reliable measure of toxin intake (Middleton \& Morice, 2000). Long-term exposure has been associated with a number of chronic conditions (e.g., Silverstein, 1992; Cheng et al., 2010; Bye et al., 2008). The development of portable CO monitors allows for the immediate assessment of toxin intake and is therefore a reliable method for self-monitoring.

\section{Methods}

Participants were recruited following participation in a study looking at the use of NRT for temporary abstinence and/or smoking reduction among those unable or unwilling to quit smoking (Beard et al., in press). Participants were given a $\mathrm{CO}$ monitor and asked to use it regularly throughout the day for 6 weeks, with the aim of maintaining their CO reading below $10 \mathrm{ppm}$ (a threshold representing very light smoking). They were advised to use nicotine replacement therapy as well, but this was not provided. There are multiple CO monitors on the market. The one used in the current study is known as the COmpact $^{\mathrm{TM}}$ Smokerlyzer ${ }^{\circledR}$ (Bedfont Scientific Ltd). This was chosen as it is small, easy to use, and is affordable to smokers. LEDs light up instantly on the screen using a familiar 'traffic light' system, which represents the level of carbon monoxide - Level 1 (green) 01-06 ppm, Level 2 (orange) $07-10 \mathrm{ppm}$, level 3 (red) 11-15 ppm, level 4 (red) 16-25 ppm, Level 5 (red) 26-35 ppm, Level 6 (red) 36-50 ppm, level 7 (flashing) 51-60 ppm.

At baseline, cigarette consumption, nicotine dependence, NRT use, past attempts to quit smoking, difficulty of these past attempts, motivation to quit and CO levels were recorded. Participants were also asked if they were currently attempting to reduce their cigarette consumption, if they had done so in the past, and if they ever modified how they smoked their cigarettes. Nicotine dependence was measured using time to first cigarette of the day (Fagerstrom, 2003), while motivation to quit by asking: 'Which of the following best describes you?' (a) I really want to stop smoking and intend to in the next month, (b) I really want to stop smoking and intend to in the next 3 months, (c) I really want to stop smoking but I don't know when I will, (d) I want to stop smoking and hope to soon, (e) I want to stop smoking but haven't thought about when, (f) I think I should stop smoking but I don't really want to, (g) I don't want to stop smoking, (h) Don't know.
During the first 2 weeks, participants were instructed to record daily their cigarette consumption, usage of the CO monitor and NRT, average CO levels, and whether they had attempted to keep their reading below $10 \mathrm{ppm}$. Participants were also asked whether they found their CO monitor helpful and easy to use, and instructed to briefly explain why. At follow-up, baseline measures were repeated. Smokers were also asked whether they had attempted to quit smoking, if yes, how long the quit attempt had lasted, about their usage of the $\mathrm{CO}$ monitors in the previous 4 weeks, and to provide further details of their views and experiences of using the $\mathrm{CO}$ monitors for smoking reduction. Participants were paid $£ 50$ to cover expenses.

\section{Analysis}

$T$ test analyses were used to determine whether there was a significant difference in cigarette consumption at baseline, during the first 2 weeks, and at the 6-week followup. Descriptive statistics are given for all other findings. Smoker' views about the use of CO monitors for smoking reduction were coded into six predetermined categories: (1) difficulties attaining a value of $10 \mathrm{ppm}$ or lower, (2) difficulties using the monitor, (3) ease of use, (4) effect on cigarette consumption, (5) effect on motivation to quit and (6) reasons why they found the monitor helpful.

\section{Results}

Ten smokers were recruited; five females and five males, with an average age of 48.6 years ( $S D$ 11.56) and cigarette consumption of 14.1(SD 6.03) cigarettes per day. Two were retired, one unemployed and seven in full-time work. Seven smoked standard cigarettes and four rolled tobacco. Only two reported that they were currently using NRT. Three reported smoking within 5 minutes of wakening, three between 6 and 30 minutes of wakening, and 4 between 31 and 60 minutes of wakening. Two reported that they really wanted to stop smoking in the next month, seven that they really wanted to stop smoking but did not stipulate when, and one smoker that they didn't want to but thought they should. All ten had quit smoking at least once in the past for an average of 15.6 (SD 6.48) weeks, eight of which reported that they found it difficult to remain abstinent. Seven of the smokers were currently reducing their cigarette consumption and seven were modifying their smoking behaviour. Nine reported that they had attempted to cut down in the past. Two had a CO reading of 11-15 ppm, one 16-25 ppm, four 26-35ppm, two 36-50 ppm and one 51-60 ppm.

Four smokers used NRT during the first couple of weeks; only two on a regular basis. Over the course of the first 2 weeks, $79.3 \%$ ( $n=111 / 140$ responses) of participants reported that they found the CO monitor helpful, and $55.7 \%$ ( $n=78 / 140$ responses) reported that they found the monitor easy to use. Smokers used the monitor on average 2.9 ( $S D$ 1.49) times per day. Nine smokers completed the 4-week follow-up. During weeks 2 to 6 , five smokers reported that they had used NRT. Four of the 


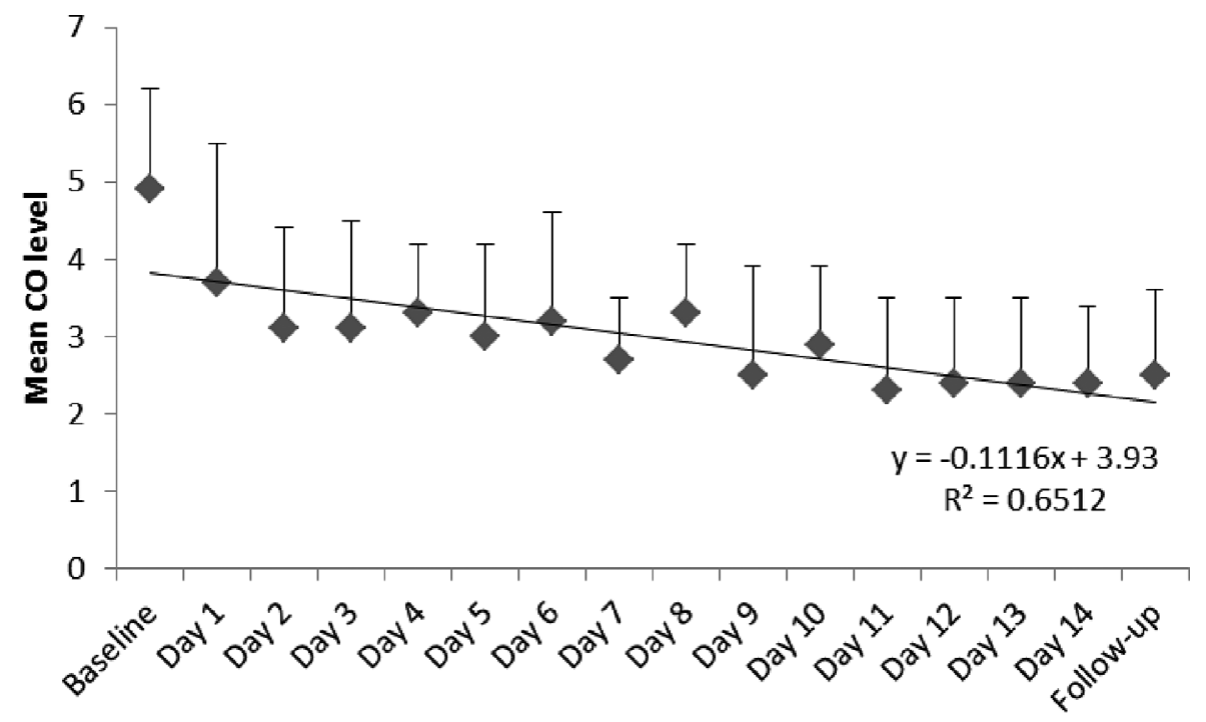

\section{Figure 1}

Graph of average Carbon Monoxide (CO) levels over time

respondents had used their $\mathrm{CO}$ monitor daily during these 4 weeks; the other three had used their monitor around 34 times per week. Six of those followed up had attempted to keep their reading below level 2 .

Eight smokers had peak daily CO concentrations below their baseline on at least $13(92.9 \%)$ of the 14 days requiring daily monitoring. Three had $\mathrm{CO}$ levels below $10 \mathrm{ppm}$ on $36 \%$ of the days, one on $21 \%$ of the days, and two on $7 \%$ of the days. Five smokers had CO levels below $15 \mathrm{ppm}$ on at least $50 \%$ of the days. At the 6-week followup, all participants had CO concentrations below their baseline value; two were below $10 \mathrm{ppm}$ and four below 15 ppm. Four had dropped 3-4 levels on the CO monitor from baseline, while five had dropped 1-2 levels. Over the six weeks there appeared to be a significant decline in the mean carbon monoxide score $(r=0.82, t=5.36, d f 14$, $p=0.001$; see Figure 1).

Average daily cigarette consumption reduced from 14.1 ( $S D$ 6.03) at baseline to 9.8 (SD 4.95) during the two weeks of daily CO monitoring $(t=2.46, \mathrm{df} 9, p=0.036)$ and to $9.5(S D$ 5.50) at 6-weeks follow up $(t=1.73, d f$ $7, p=0.127)$. Seven of the smokers reported that they felt as though the monitors had reduced their cigarette consumption and eight reported that they had modified how they smoked their cigarettes. Six smokers reported a lower nicotine dependency relative to baseline. Over the six weeks there appeared to be a significant decline in the number of cigarettes smoked per day $(r=0.81$, $t=5.17$, df 14, $p=0.001$; see Figure 2). At follow-up, one participant had quit smoking. A further four smokers

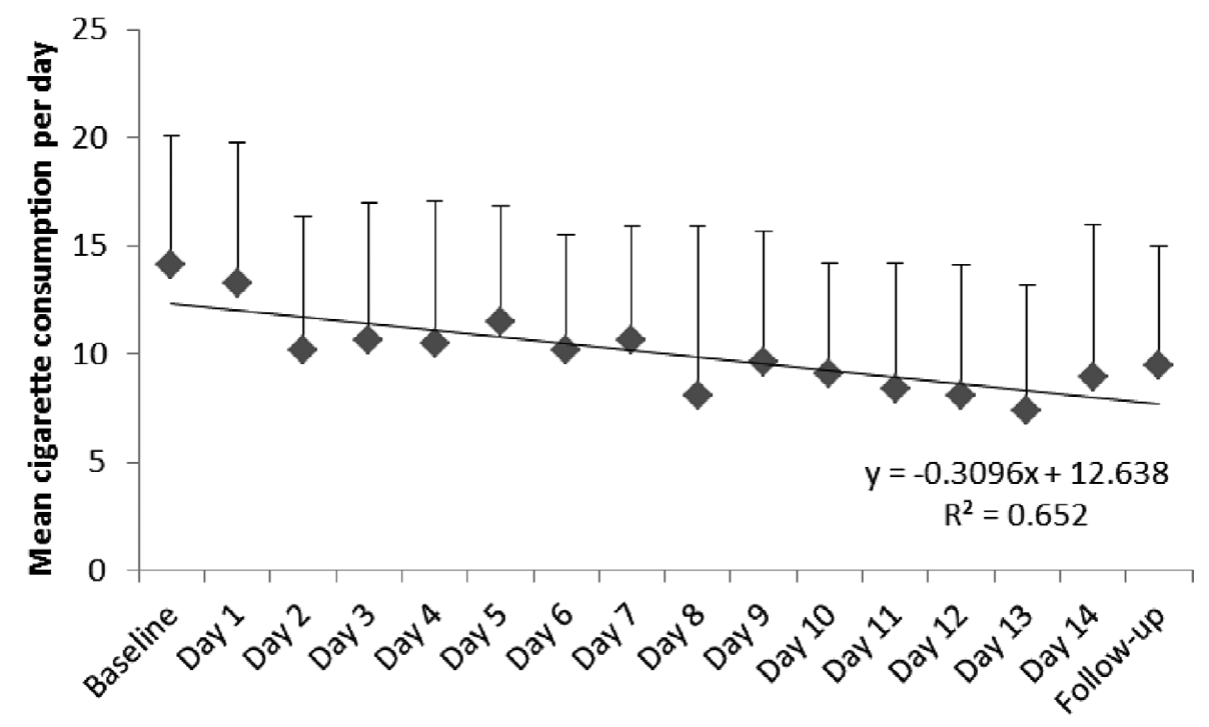

Figure 2

Graph of average cigarette consumption over time 
Table 1

Smokers Views and Beliefs on the Use of Carbon Monoxide Monitors for Smoking Reduction

\begin{tabular}{|c|c|c|}
\hline Theme & Subthemes & Example \\
\hline $\begin{array}{l}\text { 1. Difficulty attaining a } \\
\text { value of } 10 \mathrm{ppm} \text { or lower }\end{array}$ & & $\begin{array}{l}\text { 'Finding it difficult to get it down to 2.' } \\
\text { 'Trying to get the reading down to 2, but it is showing 3.' } \\
\text { 'Hard to get to 2. A strong urge to smoke if I wasn't busy.' } \\
\text { 'Hard to keep readings under 2.' } \\
\text { 'Found it hard to keep the reading below 3.' } \\
\text { 'Found it quite helpful but could not keep it below 2.' } \\
\text { 'Cannot get reading down at the moment.' }\end{array}$ \\
\hline \multirow[t]{5}{*}{$\begin{array}{l}\text { 2. Difficulties with using the } \\
\text { monitor }\end{array}$} & $\begin{array}{l}\text { a. Forget to use it } \\
\text { b. Difficult to carry }\end{array}$ & $\begin{array}{l}\text { 'To remember to use it.' } \\
\text { 'After two weeks it's a bit difficult to carry around, if it was smaller } \\
\text { it would be much better.' }\end{array}$ \\
\hline & c. Find it hard to hold breath & $\begin{array}{l}\text { 'Very easy to use, but when going out a bit clumsy.' } \\
\text { 'Holding my breath was difficult, but otherwise OK.' } \\
\text { 'I found just the first time using a slight challenge and holding my } \\
\text { breath for so long quite hard.' }\end{array}$ \\
\hline & d. Embarrassing & $\begin{array}{l}\text { 'I usually only use it when no one is looking.' } \\
\text { 'I am finding it a bit embarrassing to use in public.' }\end{array}$ \\
\hline & e. Lack of confidence & $\begin{array}{l}\text { 'First day I used it, so I feel you need to get used to and have } \\
\text { confidence in the monitor.' }\end{array}$ \\
\hline & f. Not accurate enough & $\begin{array}{l}\text { 'As time goes on I tend to be thinking that readings } 2 \text { to } 4 \\
\text { periodically through the day isn't too bad. This is because there } \\
\text { appeared to be no difference in the readings if you smoked } 20 \\
\text { cigarettes or } 16 \text { cigarettes.' } \\
\text { 'I think it should be more precise. Same readings given if you } \\
\text { smoked } 15 \text { or } 19 \text { cigarettes per day.' }\end{array}$ \\
\hline 3. Ease of use & & $\begin{array}{l}\text { 'The technique of using the machine was easy' } \\
\text { 'Easy to use. Very used to it now.' } \\
\text { 'Easy because I'm used to it and how to work it and what to expect.' } \\
\text { 'It's getting easier with practice and more use.' } \\
\text { 'Easy to operate and carry.' } \\
\text { 'Easy to follow instructions and to operate.' } \\
\text { 'Always left the monitor in view. Very simple.' } \\
\text { 'Has become part of my routine.' }\end{array}$ \\
\hline \multirow[t]{3}{*}{$\begin{array}{l}\text { 4. Effect on cigarette } \\
\text { consumption }\end{array}$} & a. Increased motivation to reduce & $\begin{array}{l}\text { 'It is encouraging me to think about cutting down.' } \\
\text { 'I am thinking that I do not need to smoke every morning.' }\end{array}$ \\
\hline & b. Reduced cigarette consumption & $\begin{array}{l}\text { 'I smoked a lot less due to the previous readings. It's making me } \\
\text { think about leaving longer gaps between cigarettes. Longer generally.' }\end{array}$ \\
\hline & c. Modification of smoking & $\begin{array}{l}\text { 'It is making me cut down.' } \\
\text { 'Today I only smoked about } 1 / 2 \text { a cigarette.' } \\
\text { 'Trying } 2 \text { smoke } 1 / 2 \text { cigarette instead.' } \\
\text { 'Out all day and didn't even think about smoking when I got home.' } \\
\text { 'Each day I notice I'm not as obsessed with smoking. It's getting easier.' }\end{array}$ \\
\hline $\begin{array}{l}\text { 5. Effect on motivation to } \\
\text { quit }\end{array}$ & & $\begin{array}{l}\text { 'I have got used to giving up.' } \\
\text { 'It is helpful and I can see it can help give up smoking.' } \\
\text { 'I do not have cravings and I am hoping to stop smoking.' } \\
\text { 'The CO monitor is making me think about stopping smoking.' }\end{array}$ \\
\hline \multirow[t]{3}{*}{$\begin{array}{l}\text { 6. Why is the monitor } \\
\text { helpful }\end{array}$} & a. Feel guilty for smoking & $\begin{array}{l}\text { 'I smoked one cigarette and felt guilty.' } \\
\text { 'Because if I didn't smoke it showed a low reading which was good } \\
\text { and when I couldn't last without a cigarette the reading was } \\
\text { high and then I felt guilty. I had the proof of the effect on my lungs.' }\end{array}$ \\
\hline & b. Rewarding & $\begin{array}{l}\text { 'Makes me feel guilty and weak.' } \\
\text { 'Low reading is a good reward.' }\end{array}$ \\
\hline & c. See effect when don't smoke & $\begin{array}{l}\text { 'Better reading today. Encouraging.' } \\
\text { 'You can see you are staying clean.' }\end{array}$ \\
\hline
\end{tabular}




\section{Table 1}

Continued

\begin{tabular}{|c|c|c|}
\hline Theme & Subthemes & Example \\
\hline & & $\begin{array}{l}\text { 'It's useful to track the difference when you have a few puffs and } \\
\text { then using the monitor.' }\end{array}$ \\
\hline & d. See effect of second hand smoke & $\begin{array}{l}\text { 'Being in the same room as smokers makes my reading go up. So } \\
\text { not happy. Have to avoid.' }\end{array}$ \\
\hline & \multirow[t]{2}{*}{$\begin{array}{l}\text { e. More awareness of smoking's effect on the } \\
\text { body }\end{array}$} & 'This had made me aware of smoking and CO levels.' \\
\hline & & $\begin{array}{l}\text { 'The CO monitor is making me think about what smoking is doing } \\
\text { to my body.' }\end{array}$ \\
\hline & f. Readings are higher than anticipated & $\begin{array}{l}\text { 'To show me that my CO reading is higher than I imagined it } \\
\text { would be' }\end{array}$ \\
\hline & g. To see how much inhaling & $\begin{array}{l}\text { 'To reflect how much I've been smoking — how much smoke I'm } \\
\text { inhaling.' }\end{array}$ \\
\hline & \multirow[t]{2}{*}{ h. See effect of NRT } & $\begin{array}{l}\text { 'To show if it's a lower reading when I use nicotine replacement } \\
\text { therapy.' }\end{array}$ \\
\hline & & $\begin{array}{l}\text { 'Helpful to show me that I smoke more without the replacement } \\
\text { gum (I have run out until I get more) therefore my reading goes up.' }\end{array}$ \\
\hline
\end{tabular}

had attempted to quit smoking; one had quit for 2-4 weeks and three had quit smoking for 1-2 days. Three smokers reported that their motivation to stop had increased.

Analysis of the statements provided by participants showed that many found it difficult to reduce their cigarette consumption so as to attain a $\mathrm{CO}$ value of less than $10 \mathrm{ppm}$ (Theme 1). They also reported a number of difficulties with the monitors, including forgetting to use them (Theme 2.a), that they were difficult to carry (Theme 2.b), and initial problems with holding their breath for an adequate time prior to blowing into the monitor (Theme 2.c). Some of the smokers also reported that they found them embarrassing to use in public (Theme 2.d), that you need to first develop confidence in the monitor (Theme 2.e), and that the measurements were not accurate enough (Theme 2.f). Nevertheless, the monitors were deemed easy to use (Theme 3 ), increased motivation for smoking reduction (Theme 4.a), and resulted in reports of reduced cigarette consumption (Theme 4.b) and urges to smoke (Theme 4.d); as well as reports of modified smoking behaviour (Theme 4.c). A number of smokers also stated that the monitor had encouraged them to think about smoking cessation (Theme 5). The CO monitors were viewed to be helpful as they made smokers feel guilty about smoking (Theme 6.a); were rewarding (Theme 6.b); allowed comparisons between times when they did and didn't smoke (Theme 6.c); and picked up the effect of environmental smoke (Theme 6.d). Smokers also reported that it made them more aware of the effects of smoking on their body (Theme 6.e), demonstrated that their CO consumption was higher than anticipated (Theme 6.f), indicated the amount of smoke inhaled from each cigarette (Theme 6.g), and provided a picture of the effect of NRT on cigarette consumption (Theme 6.h; See Table 1).

\section{Discussion}

This study examined whether providing smokers with a personal monitor for measuring expired-air $\mathrm{CO}$ with the specific goal to reduce $\mathrm{CO}$ levels below $10 \mathrm{ppm}$, would be a feasible method of achieving a reduction in smoke intake. Although the majority of smokers failed to keep their average daily $\mathrm{CO}$ concentrations below $10 \mathrm{ppm}$, average readings were below their baseline levels. Average daily cigarette consumption and nicotine dependency also reduced from baseline to follow-up. Use of the CO monitors was found to be acceptable and to increase motivation to stop smoking, with half of participants reporting an attempt to quit smoking.

Previous studies have detailed the problems smokers experience in regulating their intake (Sayette, 2004; Beard, Vangeli, Michie, \& West, in press). The results here not only suggest that using $\mathrm{CO}$ monitors and the setting of specific goals may eliminate these issue, but that it could be a reliable method for reducing smokers' toxin intake and increasing motivation to stop completely. This is despite low levels of NRT use. As smoking reduction with NRT is superior to reduction without pharmacological help, it may be anticipated that even greater benefits may be attained if smokers are actively encouraged to use medicinal nicotine (Moore et al., 2009; Beard et al., 2011). A controlled trial with long-term follow-up is warranted to further assess the implications of using $\mathrm{CO}$ monitors for self-regulation of smoking behaviour.

\section{Conclusions}

Regular personal CO monitoring with the specific goal to reduce smoking below $10 \mathrm{ppm}$ may be a useful method for reducing smokers' intake of smoke and increasing their motivation to stop completely. 


\section{Acknowledgments}

This study was funded by Cancer Research UK. The CO monitors were provided by Bedfont Scientific Ltd (http://www.bedfont.com/).

\section{References}

Abraham, C., \& Michie, S. (2008). A taxonomy of behaviour change techniques used in interventions. Health Psychology, 27, 379-387.

Barton, K.A., Blanchard, E.B., \& Veazy, C. (1999). Selfmonitoring as an assessment strategy in behavioural medicine. Psychological Assessment, 11(4), 490-497.

Beard, E., McNeill, A., Aveyard, P., Fidler, J., Michie, S., \& West, R. (2011). Use of nicotine replacement therapy for smoking reduction and during enforced temporary abstinence: A national survey of English smokers. Addiction, 106(1), 197204.

Beard, E., Fidler, J., \& West, R. (2011). Is use of nicotine replacement therapy while continuing to smoke associated with increased nicotine intake? Psychopharmacology, 218(3), 609610.

Beard, E., Vangeli, E., Michie, S., \& West, R. (in press). The use of nicotine replacement therapy for smoking reduction and temporary abstinence: An interview study. Nicotine \& Tobacco Research.

Becona, E., \& Vazquez, F.L. (2001). Effectiveness of personalised written feedback through a mail intervention for smoking cessation: A randomised-controlled trial in Spanish smokers. Journal of Consulting and Clinical Psychology, 69, 3340.

Bye, A., Sørhaug, S., Ceci, M., Høydal, M.A., Stølen, T., Heinrich, G., ... Wisløff, U. (2008). Carbon monoxide levels experienced by heavy smokers impair aerobic capacity and cardiac contractility and induce pathological hypertrophy. Inhalation Toxicology, 20(7), 635-646.

Carver, C.S., \& Schneier, M.E. (1982). Control theory: A useful conceptual framework for personality, social, clinical and health psychology. Psychological Bulletin, 92, 111-135.

Cheng, S., Lyass, A., Massaro, J.M., O’Connor, G.T., Keaney, J.F., \& Vasan, R.S. (2010). Exhaled carbon monoxide and risk of metabolic syndrome and cardiovascular disease in the community. Circulation, 122, 1470-1477.
Fagerström, K. (2003). Time to first cigarette; the best single indicator of tobacco dependence? Monaldi Archives for Chest Disease, 59(1), 91-94.

Fagerström, K.O., \& Hughes, J.R. (2002) Nicotine concentrations with concurrent use of cigarettes and nicotine replacement: a review. Nicotine \& Tobacco Research, 4(2), S73S79.

Helzer, J.E., Badger, G.J., Rose, G.L., Mongeon, J.A., \& Searles, J.S. (2002). Decline in alcohol consumption during two years of daily reporting. Journal of Studies on Alcohol, 63, 551558.

Locke, E., \& Lantham, G.P. (1990). A theory of goal setting and task performance. Englewood Cliffs, NJ: Prentice Hall.

Locke, E.A., \& Latham, G.P. (2004). What should we do about motivation theory? Six recommendations for the 21 st century. Academy of Management Review, 29, 388-403.

McAteer, J., Stone, S., Roberts, J., \& Michie, S. (2007). Use of performance feedback to increase hand-hygiene and behaviour. Journal of Hospital Infection, 66, 291-292.

Michie, S., Abraham, C., Whittington, C., McAteer, J., \& Gupta, S. (2009). Effective techniques in healthy eating and physical activity interventions: A meta-regression. Health Psychology, 28(6), 690-701.

Michie, S., Hyder, N., Walia, A., \& West, R. (2011). Development of a taxonomy of behaviour change techniques used in individual behavioural support for smoking cessation. Addictive Behaviours, 36, 315-319.

Middleton, E.T., \& Morice, H. (2000). Breath carbon monoxide as an indication of smoking habit. Chest, 117(3), 758-763.

Moore, D., Aveyard, P., Connock, M., Wang, D., Fryu-Smith, A., \& Barton, P. (2009). Effectiveness and safety of nicotine replacement therapy assisted reduction to stop smoking: Systematic review and meta-analysis. British Medical Journal, 338,1024 .

Quinn, P.D., \& Fromme, K. (2010). Self-regulation as a protective factor against risky drinking and sexual behavior. Psychology of Addictive Behaviors, 24(3), 376-385.

Sayette, M.A. (2004). Self-regulatory failure and addiction. In R.F. Baumeister \& K.D. Vohs (Eds.), Handbook of selfregulation (pp. 447-465). New York: Guilford Press.

Silverstein, P. (1992). Smoking and wound healing. The American Journal of Medicine, 93, S22-S24. 